RESEARCH REPORT

\title{
The effect of dislike of school on risk of teenage pregnancy: testing of hypotheses using longitudinal data from a randomised trial of sex education
}

\author{
C Bonell, E Allen, V Strange, A Copas, A Oakley, J Stephenson, A Johnson
}

J Epidemiol Community Health 2005;59:223-230. doi: 10.1136/jech.2004.023374

See end of article for authors' affiliations

Correspondence to

Dr C Bonell, Public and

Environmental Health

Research Unit, London

School of Hygiene and

Tropical Medicine, Keppel

Street, London WC1E 7HT,

UK; chris.bonell@

Ishtm.ac.uk

Accepted for publication

9 July 2004

Study objective: To examine whether attitude to school is associated with subsequent risk of teenage pregnancy. To test two hypotheses that attitude to school is linked to pregnancy via pathways involving young people having "alternative" expectations or deficits in sexual health knowledge and confidence. Design: Analysis of longitudinal data arising from a trial of sex education. Examination of associations between attitude to school and protected first sex, unprotected first sex, unprotected and protected last sex, and pregnancy, both crude and adjusting in turn for expectation of parenting by age 20, lack of expectation of education/training at age 20, and sexual health knowledge and confidence.

Setting: Schools in central and southern England.

Participants: Girls of median age 13.7 years at baseline, 14.7 years at follow up 1, and 16.0 years at follow up 2.

Main results: In unadjusted analysis, attitude to school was significantly associated with protected and unprotected first sex by follow up 1, protected first sex between follow up 1 and 2, unprotected last sex, and pregnancy. Dislike of school was more strongly associated with increased risk of these outcomes than was ambivalence to school. These associations remained after adjusting for socioeconomic status and for expectation of parenting, lack of expectation of education/training, and various indicators of knowledge and confidence about sexual health.

Conclusions: Dislike of school is associated with subsequent increased risk of teenage pregnancy but the mechanism underlying any possible causal link is unlikely to involve "alternative" expectations or deficits in sexual health knowledge or confidence.

$\mathrm{P}$ revious studies report that low educational attainment predicts teenage pregnancy. ${ }^{1}$ However, few studies have examined the association between attitude to school and teenage pregnancy and those that have provide inconsistent findings. ${ }^{2-4}$ We have previously reported associations between dislike of school and cognitive/behavioural indicators of risk of teenage pregnancy among 13/14 year olds in baseline data from a randomised trial of sex education. ${ }^{5}$ After adjusting for socioeconomic disadvantage, dislike of school was associated with heterosexual intercourse, expecting heterosexual intercourse by age 16 , and expecting parenthood by age 20 , but not with low knowledge of contraception or low confidence negotiating sex.

From these findings, we developed an "alternative expectation" hypothesis regarding how dislike of school might increase risk of teenage pregnancy: some young people who dislike school consequently do not develop "conventional" expectations about involvement in education/training in their late teens and view parenting as an acceptable alternative. We concluded that another hypothesis, namely that some young people dislike and are disengaged from school and consequently do not develop the knowledge and confidence necessary to avoid teenage pregnancy (the "knowledge and confidence deficit" hypothesis), was not supported by our findings. However, we could not establish dislike of school as a predictor of teenage pregnancy nor explore the plausibility of each hypothesis with much certainty because we could not examine temporality and because our data provided limited information about the risk of, and no information about the occurrence of, teenage pregnancy.

\section{Aims of this analysis}

We now aim to re-examine associations between attitude to school and risk of teenage pregnancy, and explore the plausibility of our two hypotheses of causality using longitudinal data, where measurement of exposures precedes those of outcomes, and with more valid outcome measures. In this analysis, we focus only on girls because the "alternative expectation" hypothesis is particularly applicable to this group, given that women's decisions about sexual behaviour are more likely to be influenced by their future expectations about parenting. ${ }^{6}$

\section{METHODS}

\section{Data collection}

We analysed baseline and two sets of follow up data from girls in two school year cohorts in 27 mixed sex comprehensive schools in central and southern England within a cluster trial of sex education, 14 in the intervention arm, and 13 in the comparison arm. ${ }^{7}$ Students completed questionnaires in lesson time and, where possible, questionnaires were administered and collected in by researchers. Initial data were collected in 1997 when the pupils were aged 13/14. The first follow up occurred when the participants were aged 14/ 15 and the second follow up when participants were aged 15/ 16. Questionnaires addressed demography, knowledge, attitudes, skills, behaviour, pregnancy, and views on school and sex education. Many of the questions used were based on the questionnaire used previously by Wight et al. ${ }^{8}$ Permission was sought from parents/carers for students to participate. The study was approved by University College London ethics committees. 


\section{Analysis}

We examined several exposures. Our main exposure, attitude to school, was measured using girls' responses to the statement "I like school". Girls disagreeing or strongly disagreeing were defined as "disliking school". Those neither agreeing nor disagreeing were defined as "ambivalent". Socioeconomic disadvantage was measured using two binary indicators. The first was created from responses to a question about living accommodation. Those reporting non-privately owned accommodation were categorised as disadvantaged. The second variable was created from responses to a question about parental employment. Those indicating that no parent/ guardian worked full time were categorised as disadvantaged. Both are validated indicators of socioeconomic disadvantage. ${ }^{9} 10$

We examined expectation of parenting by age 20 using a five point ordinal variable reflecting degree of agreement with a statement about this matter. Those agreeing/strongly agreeing were categorised as expecting parenting, those disagreeing/strongly disagreeing were categorised as not expecting this, and those replying they were uncertain were categorised thus. Lack of expectation of being in higher education or training at age 20 was examined via five point ordinal scale responses to two statements on expectations of education and training. Those disagreeing/strongly disagreeing with both statements or disagreeing/strongly disagreeing with one and not answering the other were categorised as lacking expectation. Those agreeing or strongly agreeing with either item were categorised as having this expectation. Those unsure about both statements, unsure about one statement and not answering the other or disagreeing/ strongly disagreeing with one statement and being unsure about the other were categorised as uncertain.

Knowledge of timing of emergency contraception was examined using a binary measure based on girls answering a question about this correctly. Knowledge of access to contraception and sexual health services was examined using a categorical indicator based on the number of correct answers from a total of four questions about these matters. Confidence in rejecting unwanted sex was examined using a categorical measure based on "easy" or "very easy" responses to a question about ease of saying "no" to this. Confidence about communicating about sex and condom use with a partner was examined using a categorical indicator based on positive responses to two questions with ordinal five point responses scales denoting easiness. All exposure measures are derived from questionnaire responses from the round of questionnaire surveying immediately prior to that from which outcomes are derived.

We examined several outcomes. Questions about girls' first experience of heterosexual intercourse (henceforth termed "sex") were asked at baseline and follow up 1 and 2 . Questions about girls' last sex and pregnancy were asked at follow up 2. Questions about first and last sex were followed by questions about use of contraception in these episodes. Sex without contraception was deemed "unprotected" while sex with contraception was "protected". Students' feedback indicated they could answer questions about their experience of sex more honestly with age. Consequently if a later response contradicted earlier ones the last response was recoded.

The first aim of analysis was to examine whether attitude to school was associated with our outcomes in crude analysis and after adjusting for indicators of socioeconomic status, as in our previous analysis. The second aim was to examine the plausibility of each of our earlier stated hypotheses in explaining any association between attitude to school and our outcomes. To do this, we examined the effect on these associations of adjusting successively and specifically for each expectation variable and then for each knowledge and confidence variable. Any substantial change in the associations between dislike of school and the outcomes, after adjustment for alternative future expectations, or for indicators of knowledge and confidence would provide evidence in support of, respectively, the "alternative expectation" hypothesis or the "knowledge and confidence deficit" hypothesis.

For first sex, our analysis reported odds ratios for both protected and unprotected first sex compared with no sex, using polytomous logistic regression models. Our rationale for defining both protected and unprotected first sex as indicators of risk is that it is probable that girls reporting protected first sex are more at risk of subsequent unprotected sex than those reporting no sex. To ensure all exposures were measured before outcomes, girls sexually active by baseline were excluded from this analysis.

For last sex, our analysis compared unprotected sex with protected sex among those who had sex more than once, using logistic regression. For pregnancy, our analysis considered the outcome pregnant or not by follow up 2 using logistic regression with all girls included in the analysis.

For the three category first sex outcome, the Stata 7 mlogit function was used for the polytomous logistic regression, with a robust variance estimator to account for the correlation within schools. For unprotected last sex and pregnancy, correlation between schools was accounted for using generalised estimating equations with an exchangeable correlation structure. ${ }^{11}$

No significant interactions were found between trial arm and any of the exposures and so data from both trial arms were analysed together. A significant interaction was found between the survey wave and girls' attitude to school. Consequently, the analysis of the first sex outcome was undertaken in two stages, first sex by follow up 1 and first sex between follow up 1 and follow up 2, to identify any time related patterns.

The $\mathrm{p}$ values were calculated to describe associations between explanatory factors and the outcomes described above.

\section{RESULTS}

Baseline questionnaires were completed by 4248 girls (median age 13.7 years), follow up questionnaires by 3749 (median 14.7 years) and follow up 2 questionnaires by 3230 (median 16.0 years). Table 1 describes the sample.

\section{First sex by follow up 1}

Altogether 451 (12.95\%) girls had sex between baseline and follow up l. Of those 308 (68.29\%) reported using protection and 87 (19.29\%) reported having unprotected sex. Attitude to school was significantly associated with both protected first sex compared with no sex and unprotected first sex compared with no sex by follow up 1 (table 2). Dislike of school was more strongly associated with increased risk of these outcomes than was ambivalence, and was more strongly associated with increased risk of unprotected than protected first sex. These associations were not substantially changed after adjusting for indicators of low socioeconomic status (table 3), which were themselves significantly associated with increased risk of protected and unprotected first sex (table 2).

The associations between dislike of school and protected and unprotected first sex remained unchanged after adjusting for expectation of parenting and lack of expectation of education/training (table 3), both of which were themselves significantly associated with increased risk of protected and unprotected first sex (table 2). The associations between dislike of school and protected and unprotected first sex also 


\begin{tabular}{|c|c|c|c|}
\hline \multirow[b]{2}{*}{ Measure } & & \multicolumn{2}{|l|}{ Frequency* } \\
\hline & & Baseline & Follow up 1 \\
\hline \multirow[t]{3}{*}{ Attitude to school } & Likes school & $2141 / 4230(50.61)$ & $1847 / 3739(49.40)$ \\
\hline & Ambivalent & $1437 / 4230$ (33.97) & $1215 / 3739$ (32.50) \\
\hline & Dislikes school & $652 / 4230(15.41)$ & $677 / 3739(18.11)$ \\
\hline \multirow[t]{2}{*}{ Housing tenure† } & Privately owned & $2625 / 3673(71.47)$ & N/A \\
\hline & Non-privately owned & $1048 / 3673(28.53)$ & \\
\hline \multirow[t]{2}{*}{ Parental employment } & $\begin{array}{l}\text { One or more parent/ } \\
\text { guardian in full time } \\
\text { employment }\end{array}$ & $3398 / 3964$ (85.72) & N/A \\
\hline & $\begin{array}{l}\text { Neither parent/guardian } \\
\text { in full time employment }\end{array}$ & $566 / 3964(14.28)$ & \\
\hline \multirow{3}{*}{$\begin{array}{l}\text { Expectations of } \\
\text { parenthood by age } 20\end{array}$} & Very/quite likely & 650/4206 (15.45) & $453 / 3721(12.17)$ \\
\hline & Unsure & $1203 / 4206(28.60)$ & $939 / 3721$ (25.24) \\
\hline & Unlikely/very unlikely & $2353 / 4296(15.45)$ & $2329 / 3721$ (62.59) \\
\hline \multirow{3}{*}{$\begin{array}{l}\text { Expectations of } \\
\text { education at aged } 20\end{array}$} & Very/quite likely & $2941 / 4217(69.74)$ & $2718 / 3734$ (72.79) \\
\hline & Unsure & $1131 / 4217(26.82)$ & $937 / 3734(25.09)$ \\
\hline & Unlikely/very unlikely & $145 / 4217(3.44)$ & $79 / 3734(2.12)$ \\
\hline $\begin{array}{l}\text { Knowledge of timing of } \\
\text { emergency contraceptive } \\
\text { pill }\end{array}$ & $\begin{array}{l}\text { Yes } \\
\text { No }\end{array}$ & $\begin{array}{l}953 / 4112(23.18) \\
3159 / 4112(76.82)\end{array}$ & $\begin{array}{l}1568 / 3643(43.04) \\
2075 / 3643(56.96)\end{array}$ \\
\hline \multirow{4}{*}{$\begin{array}{l}\text { Knowledge of access to } \\
\text { services/contraception } \\
\text { availability (number } \\
\text { correct of 3) }\end{array}$} & 0 & $663 / 4137(16.03)$ & $323 / 3649$ (8.85) \\
\hline & 1 & $1908 / 4137(46.12)$ & $897 / 3649(24.58)$ \\
\hline & 2 & $538 / 4137(13.00)$ & $586 / 3649(16.06)$ \\
\hline & 3 & $1028 / 4137(24.85)$ & $1843 / 3649(50.51)$ \\
\hline \multirow{2}{*}{$\begin{array}{l}\text { Confidence in saying } \\
\text { no to something sexual } \\
\text { that is unwanted }\end{array}$} & High & $2754 / 4107(67.06)$ & $2902 / 4028$ (72.05) \\
\hline & Low & 1353/4107 (32.94) & $1126 / 4028$ (27.95) \\
\hline $\begin{array}{l}\text { Confidence about } \\
\text { communicating about } \\
\text { sex and condom use } \\
\text { with partner }\end{array}$ & $\begin{array}{l}\text { High } \\
\text { Low }\end{array}$ & $\begin{array}{l}2390 / 4094(58.38) \\
1704 / 4094(41.62)\end{array}$ & $\begin{array}{l}2089 / 4029(51.85) \\
1940 / 4029(48.15)\end{array}$ \\
\hline
\end{tabular}

remained unchanged after adjusting for knowledge and confidence measures (table 3). Of these, increased confidence communicating about sex was significantly associated with increased risk of unprotected and protected first sex, and increased confidence rejecting unwanted sex, higher knowledge of emergency contraception and of contraception access were significantly associated with increased risk of protected sex but not unprotected sex (table 2).

In a fully adjusted model, dislike of school, non-privately owned housing, lack of full time parental employment, confidence communicating about sex, knowledge of emergency contraception and of contraception access remained significantly associated with increased risk of protected first sex, and dislike of school, and non-privately owned housing, expectation of parenting at age 20 and confidence communicating about sex remained significantly associated with increased risk of unprotected first sex.

\section{First sex between follow up 1 and 2}

Altogether $685(28.25 \%)$ girls had sex between follow up 1 and follow up 2. Of those, $570(83.21 \%)$ reported using protection and $103(15.04 \%)$ reported having unprotected sex. Attitude to school was significantly associated with protected first sex compared with no sex but not unprotected first sex compared with no sex between follow up 1 and 2 (table 2). Specifically, students who disliked school, but not those ambivalent to school, were at increased risk of protected first sex. The association between dislike of school and protected first sex was not changed by adjustment for indicators of socioeconomic status (table 3). There was a significant association between non-privately owned accommodation and protected sex (table 2).

The association between dislike of school and protected first sex was also not substantially modified by adjustment for either of our expectation variables or any of our knowledge and confidence variables (table 3). There were significant associations between expectation variables and both outcomes (table 2). All variables indicating higher knowledge and confidence were significantly associated with increased risk of protected first sex. However only higher knowledge of emergency contraception timing and increased confidence communicating about sex were associated with increased risk of unprotected first sex.

In a fully adjusted model, attitude to school, accommodation, confidence in rejecting unwanted sex, confidence communicating about sex and knowledge of emergency contraception timing remained associated with protected first sex, and knowledge of emergency contraception timing remained significantly associated with unprotected first sex.

\section{Last sex by follow up 2}

A total of $950(34.41 \%)$ girls reported having sex more than once. Of those $793(83.47 \%)$ reported using protection and $150(15.79 \%)$ reported having unprotected sex. Attitude to school was significantly associated with unprotected compared with protected last sex, with dislike of school being more strongly associated with increased risk of this than was ambivalence to school (table 2). Adjusting for socioeconomic status indicators had negligible effect on the association between dislike of school and unprotected last sex (table 3). The socioeconomic variables were not themselves significantly associated with this outcome (table 4).

Adjustment for lack of expectation of education/training and for expectation of parenting each had little effect on the association between dislike of school and unprotected last sex (table 3). Both expectation of parenting and lack of expectation of education/training were significantly associated with increased risk of unprotected last sex (table 4). Adjusting for knowledge and confidence variables had no effect on the association between dislike of school and 


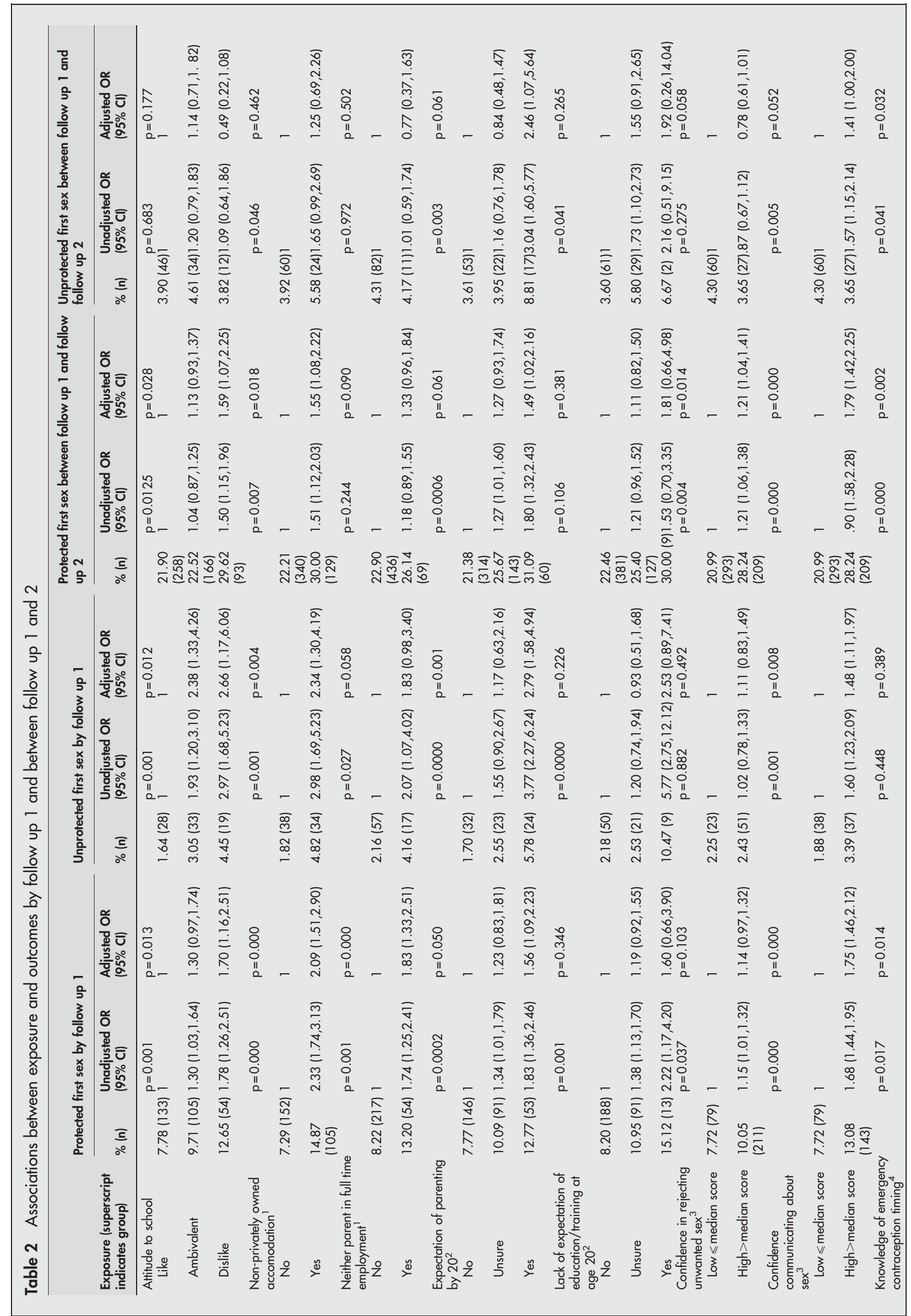




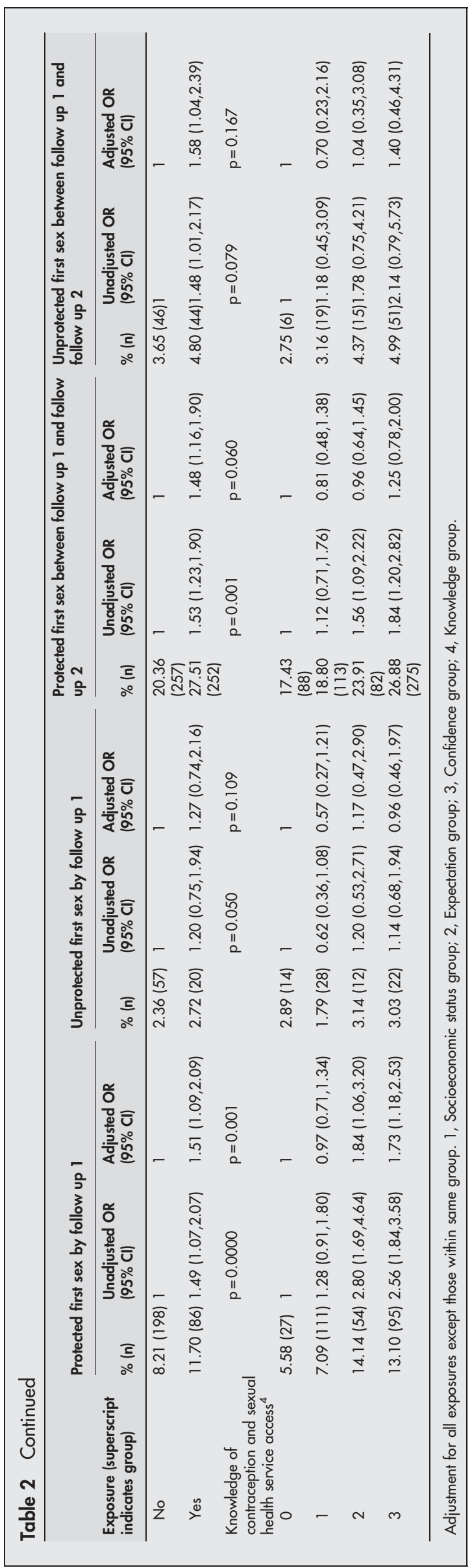

unprotected last sex (table 3). Of these exposures, only higher confidence in refusing unwanted sex was significantly associated with increased risk of unprotected last sex (table 4).

In a fully adjusted model, lack of expectation of education/ training and confidence in rejecting unwanted sex remained significantly associated with unprotected last sex.

\section{Pregnancy by follow up 2}

A total of $83(2.88 \%)$ girls reported a pregnancy by follow up 2. Attitude to school was significantly associated with pregnancy (table 4). Those girls who disliked school, but not those ambivalent to school, were at increased risk of pregnancy. The association between dislike of school and pregnancy was removed by adjusting for socioeconomic status indicators based on parental employment but not accommodation (table 3). Both these indicators of low socioeconomic status were themselves significantly associated with increased risk of pregnancy (table 4).

The association between dislike of school and pregnancy was not changed by adjusting for either expectation variable or for any of the knowledge and confidence variables (table 3). Expectation of parenting and lack of expectation of education/training were both significantly associated with increased risk of pregnancy (table 4). Of the knowledge and confidence variables, only increased confidence in rejecting unwanted sex was significantly associated with pregnancy.

In a fully adjusted model, all exposures other than knowledge of emergency contraception timing and knowledge of contraception access remained significantly associated with pregnancy.

\section{DISCUSSION}

Dislike of school was comparatively common and was associated with increased risk of all outcomes except unprotected first sex between follow up 1 and 2, and these associations remained after adjusting for socioeconomic status. In interpreting our findings some caution should be applied as the number of associations examined may have produced a small number of false positive results. None the less, our findings support our earlier suggestion that dislike of school may predispose girls to risk of teenage pregnancy.

Adjusting for expectation of parenting by age 20 and for lack of expectation of education/training at age 20 had little effect on the associations between dislike of school and our outcomes. These "alternative" expectations were themselves associated with increased risk of all outcomes, although lack of expectations regarding education/training was comparatively rare.

Adjustment for our knowledge and confidence measures also had minimal effects on the association between dislike of school and our outcomes. Our knowledge and confidence measures were not as consistently associated with outcomes as was dislike of school. Where there were associations, increased knowledge and increased confidence were each associated with increased risk of pregnancy. It is probable that these associations result from confounding by factors such as overall social confidence, which we did not attempt to adjust for in this paper but will explore in subsequent analyses.

Because adjustments for the variable discussed above did not affect the association between dislike of school and our outcomes our findings do not seem to provide support for our "alternative expectation" hypothesis or for our "knowledge and confidence deficit" hypothesis as explanations of the relation between disliking school and increased risk of teenage pregnancy, although we cannot rule out the possibility that increased knowledge and confidence are independently related to increased risk of teenage pregnancy. 


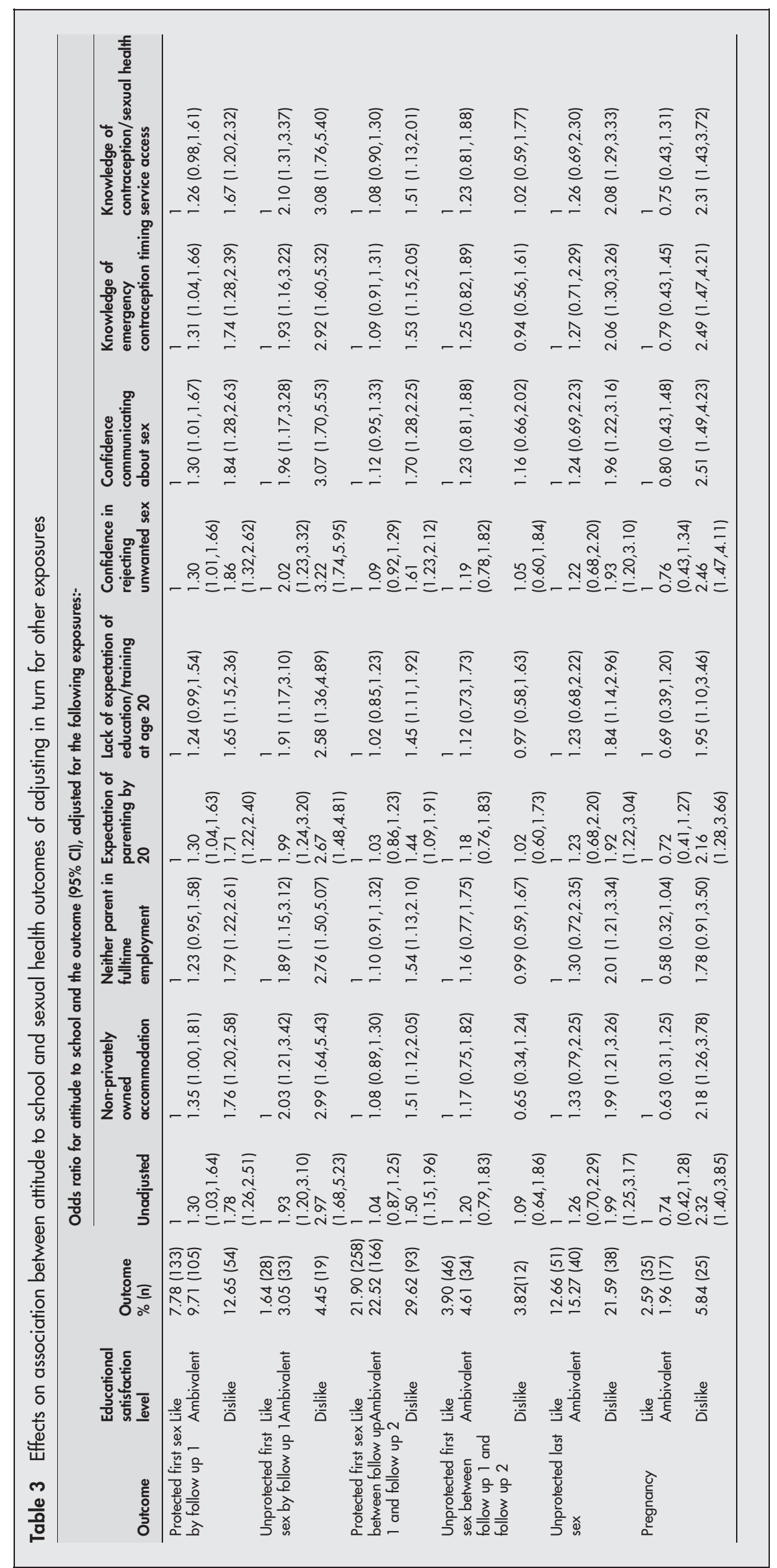


Table 4 Associations between exposure and last sex and pregnancy outcomes

\begin{tabular}{|c|c|c|c|c|c|c|}
\hline \multirow[b]{2}{*}{$\begin{array}{l}\text { Exposure (superscript } \\
\text { indicates group) }\end{array}$} & \multicolumn{3}{|c|}{ Unprotected last sex } & \multicolumn{3}{|l|}{ Pregnancy } \\
\hline & $\%(\mathbf{n})$ & $\begin{array}{l}\text { Unadjusted OR (95\% } \\
\text { CI) }\end{array}$ & $\begin{array}{l}\text { Adjusted* OR } \\
(95 \% \mathrm{CI})\end{array}$ & $\%(\mathbf{n})$ & $\begin{array}{l}\text { Unadjusted OR } \\
\text { (95\% CI) }\end{array}$ & $\begin{array}{l}\text { Adjusted* OR } \\
(95 \% \mathrm{Cl})\end{array}$ \\
\hline Attitude to school & & $p=0.008$ & $p=0.102$ & & $p=0.000$ & $p=0.013$ \\
\hline Like & $12.44(49)$ & 1 & 1 & $2.59(35)$ & 1 & 1 \\
\hline Ambivalent & $15.02(38)$ & $1.26(0.70,2.29)$ & $1.31(0.76,2.27)$ & 1.96 (17) & $0.74(0.42,1.28)$ & $0.65(0.28,1.55)$ \\
\hline Dislike & 22.09 (38) & $1.99(1.25,3.17)$ & $1.77(1.02,3.06)$ & $5.84(25)$ & $2.32(1.40,3.85)$ & $2.04(0.97,4.26)$ \\
\hline $\begin{array}{l}\text { Non-privately owned } \\
\text { accomodation }\end{array}$ & & $p=0.055$ & $p=0.119$ & & $p=0.013$ & $p=0.013$ \\
\hline No & $13.98(73)$ & 1 & 1 & $2.43(43)$ & 1 & 1 \\
\hline Yes & $18.93(46)$ & $1.42(0.99,2.04)$ & $1.38(0.92,2.06)$ & $4.59(27)$ & $1.97(1.16,3.37)$ & $1.50(0.80,2.80)$ \\
\hline Neither parent in full time & & $p=0.309$ & $p=0.127$ & & $p=0.033$ & $p=0.028$ \\
\hline No & $15.77(109)$ & 1 & 1 & $2.63(59)$ & 1 & 1 \\
\hline Yes & 12.17 (14) & $0.73(0.40,1.33)$ & $0.58(0.29,1.16)$ & 4.18 (14) & $1.65(1.04,2.61)$ & $1.93(1.07,3.46)$ \\
\hline $\begin{array}{l}\text { Expectation of parenting by } \\
20^{2}\end{array}$ & & $p=0.004$ & $p=0.632$ & & $p=0.0000$ & $p=0.032$ \\
\hline No & $13.99(68)$ & 1 & 1 & $2.52(43)$ & 1 & 1 \\
\hline Unsure & $13.73(28)$ & $0.95(0.66,1.38)$ & $0.89(0.55,1.43)$ & 1.85 (12) & $0.73(0.34,1.55)$ & $0.64(0.26,1.56)$ \\
\hline Yes & $22.31(29)$ & $1.75(1.24,2.45)$ & $1.23(0.62,2.19)$ & $7.86(22)$ & $3.29(1.95,5.54)$ & $1.83(1.01,3.33)$ \\
\hline $\begin{array}{l}\text { Lack of expectation of } \\
\text { education/training at age } 20^{2}\end{array}$ & & $p=0.003$ & $p=0.026$ & & $p=0.0000$ & $p=0.032$ \\
\hline No & $13.85(77)$ & 1 & 1 & $2.24(44)$ & 1 & 1 \\
\hline Unsure & $16.60(40)$ & $1.24(0.90,1.69)$ & $1.12(0.72,1.75)$ & $4.42(28)$ & $2.01(1.26,3.19)$ & $1.73(0.91,3.29)$ \\
\hline Yes & $38.10(8)$ & $3.90(1.59,9.58)$ & $3.85(1.25,11.87)$ & $11.36(5)$ & $5.53(2.56,11.93)$ & $4.89(1.48,16.10)$ \\
\hline $\begin{array}{l}\text { Confidence in rejecting } \\
\text { unwanted } \operatorname{sex}^{3}\end{array}$ & & $p=0.018$ & $p=0.001$ & & $p=0.253$ & $p=0.048$ \\
\hline$\leqslant$ Median score & $16.87(68)$ & 1 & 1 & $2.69(42)$ & 1 & 1 \\
\hline >Median score & $14.14(56)$ & $0.80(0.67,0.96)$ & $0.78(0.67,0.91)$ & $3.59(35)$ & $1.14(0.91,1.44)$ & $1.28(1.00,1.63)$ \\
\hline $\begin{array}{l}\text { Confidence communicating } \\
\text { about } \operatorname{sex}^{3}\end{array}$ & & $p=0.305$ & $p=0.135$ & & $p=0.000$ & $p=0.008$ \\
\hline$\leqslant$ Median score & $15.90(69)$ & 1 & 1 & $1.83(35)$ & 1 & 1 \\
\hline >Median score & $15.07(55)$ & $0.85(0.63,1.16)$ & $0.80(0.60,1.07)$ & $6.64(42)$ & $2.33(1.62,3.35)$ & $1.28(1.00,1.63)$ \\
\hline $\begin{array}{l}\text { Knowledge of emergency } \\
\text {. }\end{array}$ & & $p=0.995$ & $p=0.986$ & & $p=0.091$ & $p=0.767$ \\
\hline No & $15.40(59)$ & 1 & 1 & $2.44(35)$ & 1 & 1 \\
\hline Yes & $15.29(65)$ & $1.00(0.60,1.65)$ & $1.01(0.56,1.80)$ & $3.45(40)$ & $1.42(0.95,2.12)$ & $1.08(0.65,1.78)$ \\
\hline $\begin{array}{l}\text { Knowledge of contraception } \\
\text { and sexual health service } \\
\text { access }^{4}\end{array}$ & & $p=0.934$ & $p=0.979$ & & $p=0.015$ & $p=0.170$ \\
\hline 0 & $14.29(7)$ & 1 & 1 & $2.09(5)$ & 1 & 1 \\
\hline 1 & $13.99(20)$ & $0.96(0.43,2.14)$ & $0.87(0.34,2.22)$ & $1.23(8)$ & $0.59(0.18,1.88)$ & $0.44(0.13,1.49)$ \\
\hline 2 & $16.28(21)$ & $1.19(0.52,2.72)$ & $1.00(0.42,2.40)$ & $3.94(16)$ & $1.97(0.60,6.46)$ & $0.62(0.16,2.34)$ \\
\hline 3 & $15.61(76)$ & $1.10(0.50,2.42)$ & $0.98(0.45,2.12)$ & 3.68 (48) & $1.85(0.67,5.11)$ & $0.92(0.33,2.54)$ \\
\hline
\end{tabular}

It is possible that the lack of support for the alternative expectation hypothesis may be an artefact of limitations in our measures. It might be that fewer girls reported low expectations about future education/training than reported disliking school because of a reluctance to be negative about the future compared with the present. This might explain the limited extent to which expectation of education/training confounds the associations between dislike of school and some of our outcomes. Nevertheless, our findings do suggest that "alternative" expectations may be important risk factors for teenage pregnancy.

In conclusion, this study supports the suggestion made in our earlier paper that dislike of school may be an important determinant of subsequent risk of teenage pregnancy. It also supports the notion that lack of expectation of education/

\section{What the paper adds}

Dislike of school is associated with subsequent increased risk of teenage pregnancy but the mechanism underlying any causal link is unlikely to involve either expectations about future parenting or education/training or deficits in sexual health knowledge or confidence.

\section{Policy implications}

- In the absence of increasing school students' satisfaction with school and expectations about future education/training, interventions to reduce teenage pregnancy and improve sexual health will only be of limited effectiveness.

- Our findings should encourage the development of interventions to increase young people's satisfaction with schools and expectations about future education/ training, along with randomised trials to assess the effects of these.

training and positive expectations about becoming a parent in one's late teens might influence risk of teenage pregnancy.

However, while the study contributes to debates about the determinants of teenage pregnancy, we are able to make limited suggestions about the possible causal processes involved. Further research is needed here, particularly on the factors underlying dislike of school and lack of future expectations about education/training that might predispose to risk of teenage pregnancy. Research suggests that these factors are likely to involve a complex interplay between individual and school factors. ${ }^{12}$ 
Despite these limitations, our findings suggest that, in the absence of increasing school students' satisfaction with school and expectations about future education/training, interventions to reduce teenage pregnancy and improve sexual health will only be of limited effectiveness. Our findings should encourage the development of interventions to increase young people's satisfaction with schools and expectations about future education/training, along with randomised trials to assess the effects of these. If such interventions were to prove effective, these trials should also shed more light on possible causal processes.

\section{Authors' affiliations}

C Bonell, Public and Environmental Health Research Unit, London School of Hygiene and Tropical Medicine, UK

V Strange, A Oakley, Social Science Research Unit, Institute of Education, University of London, UK

E Allen, A Copas, J Stephenson, A Johnson, Centre for Sexual Health and HIV Research, Department of Primary Care and Population Sciences, Royal Free and University College Medical School, London, UK Funding: this study was funded by two grants from the UK Medical Research Council.

Conflicts of interest: none declared.

\section{REFERENCES}

1 Social Exclusion Unit. Teenage pregnancy. London: Cabinet Office, 1999:139.

2 Dearden K, Hale C, Alvarez J. The educational antecedents of teen fatherhood. Br J Educ Psychol 1992;62:139-47.

3 Mott FL, Fondell MM, Hu PN, et al. The determinants of first sex by age 14 in a high-risk adolescent population. Fam Plann Perspect 1996;28:13-18.

4 Paul C, Fitzjohn J, Herbison P, et al. The determinants of sexual intercourse before age 16. J Adolesc Health 2000;27:136-47.

5 Bonell CP, Strange VJ, Stephenson JM, et al. The effect of various dimensions of social exclusion on young people's risk of teenage pregnancy: development of hypotheses from analysis of baseline data arising from a randomized trial of sex education. J Epidemiol Community Health 2003;57:871-6.

6 Berrington A. Transitions to adulthood in Britain. In: Corijn M, Klizing E, eds. Transitions to adulthood in Europe. Dordrecht: Kluwer Academic, 2001:67-102.

7 Stephenson JM, Strange V, Forrest S, et al. A Randomised intervention trial of pupil-led sex education in England (RIPPLE). Lancet 2004;364:338-46.

8 Wight D, Raab GM, Henderson M, et al. Limits of teacher delivered sex education: interim behavioural outcomes from randomised trial. BMJ 2002;324:1430.

9 Oakley A, Rajan L. Social class and social support: the same or different? Sociology 1991;25:31-59.

10 Burgess S, Propper C. The dynamics of poverty in Britain. In: Hills J, Le Grand J, Piachaud D, eds. Understanding social exclusion. Oxford: Oxford University Press, 2003:44-61.

11 Liang KY, Zeger SL. Longitudinal data analysis using generalised estimating models. Biometrika 1986;73:13-22.

12 Furlong VJ. Disaffected pupils: reconstructing the sociological perspective. British Journal of Sociology of Education 1991;12:293-307. 